\section{LA DEMOCRACIA CRISTIANA Y LA IGLESIA DURANTE LA ÚLTIMA DICTADURA. CATOLICISMO, POLÍTICA Y DERECHOS HUMANOS}

THE CHRISTIAN DEMOCRACY AND THE CATHO-

LIC CHURCH DURING THE LAST DICTATORSHIP.

CATHOLICISM, POLITICS AND HUMAN RIGHTS

\section{MARIANO FABRIS •}

Investigador Adjunto del CONICET con sede en el Centro de Estudios Históricos, Universidad Nacional de Mar

del Plata

E-mail: marianofabris76@gmail.com.ar

\section{Resumen}

Este artículo busca arrojar luz sobre los vínculos existentes entre el Partido Demócrata Cristiano y la Iglesia católica en la historia reciente. Con este propósito se analizan las posiciones que asumió un grupo de dirigentes democristianos en la etapa posterior al golpe de estado de 1976 y durante la etapa de apertura política que se desenvolvió, con límites, en 1981.

\section{Registro bibliográfico}

FABRIS, MARIAN0 «La Democracia Cristiana y la Iglesia durante la última dictadura. Catolicismo, política y derechos humanos", en: ESTUDIOS SOCIALES, revista universitaria semestral, año XXVIII, $n^{\circ}$ 54, Santa Fe, Argentina, Universidad Nacional del Litoral, enero-junio, 2018, pp. 143-168.

\section{Abstract}

This article seeks to shed light on the links between the Christian Democratic Party and the Catholic Church in recent history. With this purpose, are analyzed the positions assumed by a group of Christian-democratic leaders in the postcoup d'État of 1976 and during the political opening phase that took place, with limits, in 1981.

\section{Descriptores - Describers}

Democracia Cristiana / Iglesia / dictadura / Derechos Humanos / política / religión

Christian Democracy / Church / dictatorship / Human Rights / politics / religion

Recibido: 26/01/2018 Aprobado: 15/06/2017 


\section{INTRODUCCIÓN ${ }^{1}$}

Este artículo busca arrojar luz sobre los vínculos existentes entre el Partido Demócrata Cristiano (PDC) y la Iglesia católica en la historia reciente. Con este propósito se analizan las posiciones que asumió un grupo de dirigentes democristianos en la etapa posterior al golpe de estado de 1976 y durante la apertura política que se desenvolvió, con límites, en I98I.

El vínculo del PDC con la Iglesia y, en particular, con su jerarquía no fue un tema muy abordado por los estudios históricos. De hecho, la inclusión del partido dentro de la configuración católica tal como se sostiene aquí, es un problema a indagar en cada etapa de su trayectoria y no un dato constatado. No hay que pasar por alto la inexistencia de un vínculo orgánico Iglesia-partido. Históricamente el PDC se presentó como aconfesional y la jerarquía no hizo mucho por canalizar la participación política de los laicos hacia esta opción ${ }^{2}$. Sin embargo, a pesar de lo dicho y en función de una comprensión más profunda del problema, entendemos que es importante avanzar en el estudio de coyunturas específicas y evitar generalizaciones excesivas.

El acercamiento que proponemos se nutre, principalmente, del análisis de dos revistas que durante la dictadura militar aglutinaron a militantes democristianos pertenecientes al Partido Popular Cristiano (PPC), un nucleamiento resultante de la división de la Democracia Cristiana a principios de la década de 1970. Se trata de Sintesis Socialcristiana (Sintesis), que se editó durante 1977 y Proyecto Socialcristiano (Proyecto) que apareció tres años después y se publicó hasta 1982. En las notas y columnas de opinión exploramos los posicionamientos y perspectivas de los dirigentes frente a la realidad política y analizamos sus vínculos con las lecturas provenientes de la Iglesia católica. Le prestamos especial atención al tratamiento que se le dio a la violencia política y la represión estatal y a la mirada que predo-

\footnotetext{
${ }^{1}$ Este trabajo se realizó en el marco de un proyecto en la Carrera de Investigador Científico de Conicet. Una versión preliminar fue presentada en las XVI Jornadas interescuelas/departamentos de Historia, UNMDP, 2017

${ }^{2}$ Si los obispos le hubieran reconocido al PDC la representación de los católicos, también habrían reconocido implícitamente que lo que unía a los laicos era un conjunto de concepciones representable políticamente y no, como era predominante en el Episcopado, la matriz cultural que le otorgaba a la nación su impronta. Además, brindar apoyo a un grupo de dirigentes para actuar en política en nombre de los católicos implicaba, en cierta medida, correrse del lugar central que históricamente la jerarquía había pretendido ocupar.
} 
minó frente a las denuncias sobre violaciones a los derechos humanos. Ponemos el foco en esta cuestión por varias razones. En primer término, por el lugar cada vez más importante que adquirió la cuestión en el devenir político de la última dictadura y, en particular, en sus últimos años. En segundo término, porque la jerarquía católica, tanto durante la dictadura como posteriormente, participó activamente en los debates que emergieron en torno a esta cuestión. Finalmente, porque del riñón de ese grupo de dirigentes democristianos que participaban en aquellas publicaciones emergió en 1983 la candidatura de Augusto Conte, uno de los fundadores del CELS, padre de un militante desaparecido y quien se presentó en las elecciones de aquel año como el «candidato de los derechos humanos». Enfocarnos en el tema parece, en consecuencia, una opción pertinente para indagar en el espacio de vinculación político-eclesiástica. Como sostienen Mainwaring y Scully (20I0) la relación entre la fe religiosa, la Iglesia católica y la política siguen siendo importantes para entender el rol de la democracia cristiana en Latinoamérica. Esto sería así porque los legisladores democristianos y sus votantes seguirían siendo más religiosos que los de otros partidos y porque «los cambios teológicos e institucionales de la Iglesia católica continúan influyendo en los debates sobre la religión y sus vínculos con la política» (2010: 70).

El PDC fue fundado a mediados de 1954 a partir de la articulación de diferentes corrientes democristianas, en el contexto del enfrentamiento entre Perón y la Iglesia. Su sustrato común era reducido y lo otorgaba, en lo esencial, una difusa referencia a la Doctrina Social de la Iglesia y a pensadores como Jacques Maritain o Emmanuel Mounier. El partido estuvo jalonado desde su fundación por enfrentamientos internos, fracturas y recomposiciones. Si bien inicialmente el PDC se encontró -aunque con diferentes matices- entre los grupos antiperonistas, a principios de la década de 1960 se impuso la llamada estrategia de «apertura» que priorizó la formación de frentes electorales que incluyeran a referentes del partido proscripto. En 1972 se produjo una fractura precipitada por las distintas actitudes que asumieron los principales dirigentes frente a las convocatorias al dialogo del gobierno militar. De esta fractura surgió el Partido Revolucionario Cristiano, bajo el liderazgo de Horacio Sueldo, y el PpC, conducido por José Allende. Durante la última dictadura militar (1976-1983) se logró la reunificación partidaria, aunque este proceso no implicó la desaparición de líneas internas bien definidas. Con vistas a las elecciones presidenciales de 1983 los democristianos presentaron candidatos propios, pero con escasa repercusión. Su único éxito se dio en Capital Federal donde 
el desempeño de Augusto Conte le permitió acceder a la Cámara de Diputados de la Nación. Posteriormente, el PDC volvió a integrar frentes electorales con el peronismo incentivado, al menos en parte, por el afianzamiento de la corriente renovadora liderada por Antonio Cafiero.

La bibliografía existente sobre la Democracia Cristiana es, en general, escasa. Para el período considerado en este artículo contamos con el aporte de los propios dirigentes y militantes democristianos (CERRO, I983; GHIRARDI, I983; PARERA, I986). Sus publicaciones resultan relevantes porque permiten reconstruir la trayectoria del partido desde su fundación y porque nos acercan a las experiencias y las perspectivas de los protagonistas. Desde el ámbito académico las investigaciones de Marcela Ferrari (20I7 y 20I8) proponen miradas más complejas sobre las corrientes internas del partido y sus vínculos con otros actores. Asimismo, avances recientes han permitido arrojar luz sobre la figura de Augusto Conte. Se ha reconstruido su trayectoria, forjada a partir de una multiplicidad de pertenencias (CATOGGIO, 20I7), y se ha analizado la campaña electoral que le permitió acceder al Parlamento (FABRIS, 20I8 -en prensa-). Los trabajos sobre el partido tampoco abundan para etapas previas, aunque sí es posible destacar aquellas investigaciones que prestaron alguna atención al PDC al analizar los enfrentamientos entre Perón y la Iglesia que precedieron al golpe de Estado de I955 (CAIMARI, I995; BIANCHI, 200I) y las disputas que, con eje en la cuestión peronista, se sucedieron posteriormente (SPINELLI, 2005; TOURIS, 2007). Dado que nuestra indagación sobre el PDC se inserta en una preocupación más amplia sobre el catolicismo, resulta sugerente la lectura que José Zanca ofrece sobre el lugar del partido en el proceso de secularización interna que vivió la Iglesia entre las décadas de 1950 y 1960. El autor considera que la formación del PDC expresó «la aspiración del laicado a encontrar nuevas formas de participación» (ZANCA, 20I3: I8I-I82). Zanca enfatiza que

«la aparición de la democracia cristiana y del humanismo cristiano fue el reflejo de la construcción de un laicado capaz de ejercer juicios propios e independientes. Se trataba de una esfera claramente autonomizada de la presencia clerical e iniciativas de laicos que no contaban con el beneplácito de la jerarquía y que, en muchos casos, y a pesar de la hostilidad de la misma jerarquía, resultaron exitosas en los ámbitos en los que se desplegaron» (ZANCA, 20I3: 23I). 
Teniendo presente el lugar que ocupaba el partido en el catolicismo argentino y las expectativas de autonomía que expresó su fundación, vamos a sostener que ante un contexto de clausura de los canales de participación, de un notable protagonismo de los obispos y dada la fragmentación partidaria, los democristianos tendieron a reforzar los vínculos con la jerarquía eclesiástica, consideraron a los documentos episcopales como fuente de inspiración en la elaboración de interpretaciones de la realidad por la que atravesaba el país y sobre la cual pretendían influir y atribuyeron a los obispos un papel orientador en la vida política del país. Vale aclarar que, tal como sugieren las principales investigaciones sobre la jerarquía católica durante esta etapa (ESQUIVEL, 2004; BONNIN, 2012 y FABRIS, 2OII), está disposición a otorgarle un lugar central a los obispos en la política fue un denominador común de la mayor parte de la dirigencia política. En todo caso, lo que hay que destacar para el PDC en este particular contexto, es que no hubo demasiado celo por preservar la imagen de aconfesionalidad a través de la cuál había procurado mostrarse como una propuesta atrayente más allá de los límites del catolicismo.

Según las conclusiones de otras investigaciones (FABRIS, 2OII), este proceso coincidió con una reconfiguración de las relaciones de poder en el interior de la jerarquía eclesiástica que posibilitó un mejor posicionamiento de aquellos obispos dispuestos a avanzar hacia una salida democrática en el ámbito político y proclives a aceptar una mayor participación de los laicos. Estos obispos, a quienes se puede asociar a la llamada Teología de la Cultura (EzCurRA, I988) o Teología del Pueblo (scannone, 1997), se mostraron receptivos frente algunos rasgos de la modernidad y aceptaron, con matices, el carácter plural de la sociedad argentina. Si bien a partir de estos posicionamientos tomaron cierta distancia del «mito de la nación católica», concibieron que, entre todas las dimensiones de la cultura, la religiosa cumplía un rol cardinal como fuente de sentido y al hacerlo, entendemos, expusieron una tensión entre aquella aceptación del pluralismo y la ubicación del catolicismo en el centro de la cultura. En el futuro cercano, estas perspectivas generarían roces con los nuevos discursos sobre la democracia animados por el triunfo de Raúl Alfonsín. En función del problema que indagamos en este artículo, la cuestión adquiere una importancia fundamental porque, como se verá, los dirigentes democristianos analizados no fueron ajenos a esta misma tensión.

El trabajo está organizado en dos partes. En la primera, nos concentramos en el año 1977 para analizar las perspectivas que los dirigentes democristianos expresaron sobre el contexto político y la cuestión de los DDHH a la luz de las propuestas 
episcopales. En la segunda parte, volvemos sobre estas cuestiones en una coyuntura diferente caracterizada por el desgaste acelerado del gobierno militar y la aparición de reclamos por el retorno de la democracia.

\section{UNA MIRADA DEMOCRISTIANA SOBRE EL GOBIERNO MILITAR A UN AÑO DEL GOLPE DE ESTADO}

A mediados de 1977 un grupo de dirigentes democristianos, bajo la dirección de Néstor Vicente, comenzó a editar la revista de circulación interna Sintesis. Se trataba de una publicación de pocas páginas, sin publicidades y con las características de un boletín informativo. Vale recordar que para los partidos políticos la edición de revistas o boletines y la organización de encuentros, jornadas o seminarios fue una forma de mantener cierto nivel de actividad política en el contexto dictatorial ${ }^{3}$. Sintesis aglutinó a un sector del PPC que posteriormente conformaría la corriente Humanismo y Liberación ${ }^{4}$. Dado que la revista apareció cuando se iniciaban las tratativas para alcanzar nuevamente la unidad partidaria, es probable entonces, que uno de los objetivos de sus editores haya sido incidir en ese proceso.

\section{La Iglesia: fuente de inspiración}

Un lector poco informado, con tan sólo recorrer las páginas de Sintesis, habría notado el interés de la publicación por todo lo relativo a la vida de la Iglesia. No faltaban notas y síntesis informativas, publicidad sobre encuentros de la Acción Católica, referencias habituales al Papa y declaraciones de obispos. Lo más relevante, sin embargo, es que ese lector habría sido interpelado por un discurso que, a la hora de reflexionar sobre posibles soluciones para la crisis que vivía el país, le

${ }^{3}$ Entrevista a Ricardo Parera, realizada por el autor, noviembre de 2017. Posteriormente, como bien señala Ferrari, este tipo de actividades fue una herramienta eficaz para articular la oposición al régimen militar (2017: 62).

${ }^{4}$ Esta corriente interna del PDC logró un notable protagonismo en la década de 1980. Los legisladores nacionales que el partido logró llevar al Congreso fueron miembros de esa corriente. Sobre la misma ver FERRARI, 2018. 
atribuía a la Iglesia un rol protagónico ${ }^{5}$. La publicación no dejaba de pensar en un horizonte democrático ni de tomar distancia frente a propuestas que reeditaran la unión entre «la cruz y la espada» pero, en ese contexto particular y ante la crisis más profunda que había vivido el país, las opiniones vertidas en sus páginas afirmaban que el rol histórico de la Iglesia en Argentina no se podía obviar.

Defender tal protagonismo de la Iglesia implicaba, desde la perspectiva de los dirigentes democristianos, enfrentar a quienes, a nivel global, buscaban deteriorar al catolicismo poniendo en funcionamiento «toda una maquinaria de poder en la que se asienta el anticristiano modo de vida basado en el consumo y el lucro». Eran, en definitiva, «los que se oponen a la Iglesia en cuanto esta asume una postura de compromiso temporal, denunciando injusticias y proponiendo la construcción de una nueva civilización, la civilización del amor» ${ }^{6}$.

La reiteración de citas del documento del Episcopado «Reflexión cristiana para el pueblo de la patria» ${ }^{7}$ y del libro de Vicente Zazpe, arzobispo de Santa Fe, La Patria busca su futuro (1977) en los primeros números de la revista, nos lleva a pensar que estas fueron dos fuentes que orientaron la reflexión sobre la situación del país y sobre el proyecto político acorde. Vamos a volver sobre el documento episcopal cuando abordemos la cuestión de los DDHH, ya que este fue su eje.

Las intervenciones de Zazpe sobre la actualidad política merecen una investigación particular. Se trata de uno de los obispos más citados por los medios de comunicación y los dirigentes políticos durante toda la dictadura y en especial durante sus últimos años. El libro que nutrió las reflexiones democristianas apareció en 1977 e incluyó los mensajes radiales que el arzobispo ofrecía semanalmente y que giraban en torno a la definición de un proyecto de país. Allí, Zazpe habló de un contexto particularmente difícil, pero se mostró optimista al sostener que existía «una reserva suficiente de esperanza» alimentada por los propósitos democráticos del gobierno militar (ZAZPE, 1977: II). Zazpe consideró que la suspensión de la

\footnotetext{
${ }^{5}$ Carlos Eroles sostuvo la «Argentina Porvenir» era la que, marginando «a quienes practican la violencia», se llevaría a cabo "con el aporte de todos los sectores: obreros, empresarios, profesionales, partidos políticos, Iglesia y Fuerzas Armadas», EROLES, CARLOS, «Un nuevo atentado contra la paz», Síntesis Socialcristiana, № 2, 08/1977, p. 9.

${ }^{6}$ BRUNO, ÁNGEL, «El caso Lefebvre», Síntesis Socialcristiana, №2, 08/1977, p. 11.

7 CEA, «Reflexión cristiana para el pueblo de la patria» en Documentos del Episcopado Argentino, Buenos Aires, Claretiana, 1982, pp. 311-315.
} 
actividad partidaria ayudaría «a una reflexión patriótica más serena y profunda» (p. I2) con los aportes de la Iglesia ya que el evangelio tenía «exigencias ineludibles que llegan hasta el campo de lo político» (p. 20). En última instancia, la suspensión sólo postergaba «una de las formas de participación, pero no clausura todos los modos posibles» (p. 23). En cuanto a las propuestas concretas, Zazpe sostuvo que «ha llegado la hora de mostrar la capacidad de la Argentina para dar vigencia histórica a la doctrina social cristiana, a través de un modelo societal, donde los valores humanos y cristianos sean enunciados en los objetivos, asegurados en sus metas y concretados en su realización» (p. 65). El arzobispo santafesino concluyó que el país «necesita de una ascesis nacional, que haga del amor patrio el segundo amor después de Dios y la matriz de la ansiada pacificación de los argentinos» (p. 8I). De esta lectura es posible inferir que el gobierno militar podía ser considerado, incluso por sectores que no estaban particularmente consustanciados con los objetivos del Proceso, como una oportunidad política.

En el segundo número de Sintesis, publicado en septiembre de 1977, Néstor Vicente destacó el valor de la propuesta Zazpe y coincidió con él en que el proyecto nacional «no puede consistir en transferir modelos extranjeros y aplicarlos coactivamente» $^{8}$. Asimismo, insistió en la necesidad de prestarle atención a las propuestas de orientación socialcristiana en relación a la situación social, a la planificación económica y a la función social de la propiedad privada, con las que Zazpe había cerrado su libro9. Más allá de esta referencia puntual a la propuesta del prelado, desde entonces las citas del se reiteraron en las páginas de la revista conformando una de las principales referencias a la hora de evaluar el contexto político del país. Si el uso generoso de las citas de Zazpe implicó la incorporación del discurso de un agente religioso en la construcción de una interpretación de la realidad política y social del país, al resaltar las propuestas que el obispo presentaba a título personal, también significó establecer una diferenciación al interior de la jerarquía. Está claro que la de Zazpe era una voz destacada en la Iglesia y que la distinción entre lo personal y lo institucional era borrosa en la realidad concreta, pero no es menos cierto que su discurso convivía con otros y que las diferencias

8 VICENTE, NÉSTOR, «Pluralismo y participación para disentir en unidad», Síntesis Socialcristiana, $N^{\circ} 2$, agosto de 1977, 08/1977, p. 2.

9 VICENTE, NÉSTOR, «Pluralismo y participación para disentir en unidad», Síntesis Socialcristiana, $N^{\circ} 2$, agosto de 1977, 08/1977, p. 2. 
entre ellos eran, en ocasiones, muy importantes. Hubo obispos, por ejemplo, cuyos vínculos con las FFAA y su compromiso con la represión fueron fuertes y no tuvieron espacio en la publicación democristiana.

El segundo número de la revista también incluyó una síntesis del «Coloquio Socialcristiano", un encuentro en el que participaron numerosos dirigentes del partido y que fue clausurado por una conferencia de Jorge Novak, obispo de Quilmes. En el documento que sintetizó las conclusiones del encuentro se sostuvo:

«En el marco de un necesario pluralismo de opiniones, el socialcristianismo tiene, sin embargo, ideas rectoras que lo expresan y le confieren unidad; la fe como criterio de interpretación de la historia y de la realidad presente; el respeto por la dignidad fundamental del hombre como hijo de Dios y por su libertad esencial; la valoración de la democracia como estilo de vida; la aspiración de organizar la sociedad en el marco del Estado de derecho, el bien común, el desarrollo humano integral, la justicia social y la participación popular; el ideal histórico concreto de alcanzar, en el ejercicio activo de la solidaridad, la Paz y la unidad necesaria para construir la Civilización del Amor» ${ }^{10}$.

Es necesario señalar que los dirigentes democristianos estaban lejos de ejercer algún monopolio sobre estas ideas. Es más, tal como se ha afirmado (BONNIN, 20I2; FABRIs, 2OII), en el contexto dictatorial las propuestas de la Conferencia Episcopal Argentina (CEA) pasaron a formar parte de un sustrato común del que se nutrían los discursos de una amplia gama de dirigentes políticos. La tendencia a reconocerle a la Iglesia y a sus agentes un lugar central en la política no fue, entonces, una práctica limitada al PDC y, tal como hemos señalado en otra parte (FABRIS, 2OII), mientras los militares erosionaban la figura del político tradicional, el recurso a la voz de los obispos se presentó como una vía de relegitimación sostenida en una pretendida despolitización de las propuestas en nombre de fines superiores. Más allá de que los discursos episcopales cruzaran transversalmente a la mayoría de los partidos, parece factible atribuir algún viso de singularidad a la concepción esbozada por los dirigentes democristianos según la cual la fe religiosa era un criterio para interpretar la realidad y el objetivo de la política debía ser la construcción de la «Civilización del Amor».

${ }^{10}$ LÓPEZ TABOADA, JOSÉ, «Coloquio Socialcristiano», Síntesis Socialcristiana, №3, 09/1977, p. 11. 
En el último número de 1977 la revista publicó el documento «No a la violencia, si a la Paz», firmado por los más altos dirigentes democristianos. Este documento, que en su título recuperaba el lema propuesto por el papa Pablo vi para la Jornada Mundial de la Paz de $1978^{11}$, fue presentado como un aporte en el proceso de unificación de quienes asumen «un compromiso social y político a la luz de las enseñanzas del Magisterio de la Iglesia» ${ }^{12}$. Más allá de la importancia del documento para la vida interna del partido y de acuerdo al recorrido que trazamos en este artículo, interpretamos que en sus páginas se expresó una tensión que perduraría en las posiciones que asumió el partido frente al retorno de la democracia en los años siguientes. Dicha tensión se daría entre las concepciones pluralistas sobre la sociedad y la política, por un lado, y la supuesta existencia de un ser nacional que tenía al cristianismo como fuente de inspiración, por el otro. Como sostuvieron, «la solución para nuestros problemas emerge del marco mismo del ser nacional, profundamente popular, profundamente humanista y profundamente cristiano». Los dirigentes sostuvieron, recurriendo a documentos y mensajes del Papa, que aspiraban a la conformación de una sociedad «al servicio de todo el hombre y de todos los hombres [...] Donde importe más el ser que el tener; la justicia social y la fraternidad más que la competencia; el hombre creador y no mero productor ${ }^{13}$.

\section{La Iglesia, la represión y los derechos humanos}

Según sostienen Marcos Novaro y Vicente Palermo (2003), durante la dictadura la Iglesia católica asumió una posición de distanciamiento frente a dos extremos, el de la «violencia subversiva» y el de la «represión ilegal». Está claro, y así lo han puesto de manifiesto los trabajos recientes (CATOGGIO, 20I6), que la Iglesia tuvo una relación compleja con la violencia y la represión y que en su interior convivieron algunos de los actores que mayor oposición manifestaron frente al gobierno, junto a otros que le brindaron a este la legitimación que requería en su tarea represiva. De todas maneras, en sus discursos, la mayoría episcopal se representó en una posición de distanciamiento y exterioridad frente a esta cuestión. En cierta medida esta posición podría ser considerada un ingrediente de aquello que, ya en democracia,

\footnotetext{
11 «No a la violencia, si a la Paz», Síntesis Socialcristiana, № 5, 12/1977, p. 2.

12 «No a la violencia, si a la Paz», Síntesis Socialcristiana, №5, 12/1977, p. 2.

13 «No a la violencia, si a la Paz», Síntesis Socialcristiana, №5, 12/1977, p. 11.
} 
comenzó a tomar forma como «teoría de los dos demonios» y que fue, durante el gobierno de Raúl Alfonsín, la interpretación hegemónica sobre el pasado reciente ${ }^{14}$.

Consideramos que la dirigencia democristiana reprodujo este posicionamiento y que, específicamente en este tema, sólo detrás de la figura de Augusto Conte apareció posteriormente una mirada alternativa. Esto no implica afirmar que en el partido existió una posición monolítica frente a la cuestión de los derechos humanos. Las diferencias existieron y como ha demostrado Ferrari (20I7) la corriente Humanismo y Liberación se construyó como alternativa partidaria asumiendo la defensa de los derechos humanos y los reclamos de justicia frente a dirigentes que defendían posiciones mucho más tímidas. De todas maneras, más allá de Conte, es difícil encontrar a otros dirigentes que tempranamente hayan privilegiado una participación tan comprometida en los organismos de DDHH ni que hayan elaborado una interpretación de la represión que rompiera totalmente con la idea de los excesos. «Reflexión cristiana para el pueblo de la patria» ${ }^{15}$ fue uno de los primeros documentos episcopales que planteó, con posterioridad al golpe de Estado de 1976, aquella neutralidad en la que buscaban posicionarse los obispos. Esta dirección se afianzó más tarde con los documentos Iglesia y Comunidad Nacional y Camino de Reconciliación, entre otros ${ }^{16}$. Pero esta continuidad puede resultar engañosa. Si retrospectivamente es posible trazar cierta continuidad en los discursos episcopales, su recepción en cada coyuntura fue diferente. En el documento de 1977 los obispos hicieron algunos planteos al gobierno, aunque acompańados por mensajes de apoyo y la aclaración de que no pretendían «entorpecer» su búsqueda «del bien común». Se diferenciaron explícitamente del «accionar de fuerzas ocultas, en las que entran en juego intereses de todo orden, que han desatado contra la Argentina una campaña internacional ${ }^{17}$. Entre las observaciones más críticas sostuvieron que «ninguna teoría acerca de la seguridad colectiva [...] puede hacer naufragar los

\footnotetext{
${ }^{14}$ En diciembre de 1983, en una de las pocas referencias explicitas a tal teoría, el nuevo presidente Raúl Alfonsín sostuvo: «se ha pretendido combatir el demonio con el demonio (la violencia con la violencia) convirtiendo al país en un infierno», Esquiú, 22/01/1984, p. 5.

${ }^{15}$ CEA, «Reflexión cristiana para el pueblo de la patria» en Documentos del Episcopado Argentino, Buenos Aires, Claretiana, 1982, pp. 311-315.

${ }^{16}$ CEA, Iglesia y comunidad nacional, Buenos Aires, Claretiana, 1981; CEA, Camino de Reconciliación. Buenos Aires, CEA, 1982.

17 CEA, «Reflexión cristiana para el pueblo de la patria» en Documentos del Episcopado Argentino, Buenos Aires, Claretiana, 1982, p. 311.
} 
derechos de la persona» y que sería un error «tolerar y aun aceptar [...] la licitud del asesinato del enemigo, la tortura moral y física, la privación ilegítima de la libertad o la eliminación de todos aquellos de los que pudiera presumirse que son agresores de la seguridad individual o colectiva ${ }^{18}$. Los obispos se lamentaron de que las autoridades no hayan brindado información y concluyeron que todo indicaría "que el gobierno no ha logrado aún el uso exclusivo de la fuerza»" ${ }^{19}$. Finalmente llamaron a la reconciliación, que debía estar precedida por el arrepentimiento de quienes «sembraron y continúan sembrando la subversión con violencia y odio», y a la construcción de la "civilización del amor»" ${ }^{20}$.

Este posicionamiento de los obispos cosechó reacciones dispares que sólo son comprensibles al considerar el contexto de producción del documento. Si leído desde el presente resaltan las muestras de respaldo al régimen militar y la moderación de críticas, en aquel momento, por el contrario, el documento causó disgusto en el gobierno y entre algunos de sus apoyos más característicos. La revista Cabildo, exponente del nacionalismo católico, apuntó contra el «tono transaccional» del documento y consideró que al haber olvidado «la infiltración marxista montonera en los cuadros eclesiásticos», los obispos carecerían «de todo derecho a ocuparse de los asuntos del país ${ }^{21}$. Diferente fue la valoración entre los sectores que se oponían al gobierno militar. La Asamblea Permanente por los Derechos Humanos, por ejemplo, resaltó su objetividad y claridad y lo calificó como un «valiente documento» (VERBITSKY, 2006: I66).

Entre los dirigentes democristianos el apoyo a la propuesta episcopal parece haber sido unánime. Francisco Cerro y Enrique De Vedia, dos de sus principales referentes, calificaron al documento como «excepcional» y Síntesis lo incluyó dentro de una serie de documentos fundamentales elaborados por los episcopados latinoamericanos ${ }^{22}$. A propósito, se destacó que los documentos de los obispos

${ }^{18}$ CEA, «Reflexión cristiana para el pueblo de la patria» en Documentos del Episcopado Argentino, Buenos Aires, Claretiana, 1982, p. 312.

${ }^{19}$ CEA, «Reflexión cristiana para el pueblo de la patria» en Documentos del Episcopado Argentino, Buenos Aires, Claretiana, 1982, p. 313.

${ }^{20}$ CEA, «Reflexión cristiana para el pueblo de la patria» en Documentos del Episcopado Argentino, Buenos Aires, Claretiana, 1982, pp. 314-315.

21 «Un penoso desencuentro. El Episcopado y la nación», Cabildo, N 8, 03/06/1977, pp. 27-28.

22 Síntesis Socialcristiana, № 1, 07/1977, p. 6 y AMEGLIO, MIGUEL, «La Iglesia latinoamericana y los modelos sociopolíticos», Síntesis Socialcristiana, № 1, 07/1977. 
argentinos, brasileros y chilenos aparecidos en 1977 ponían de manifiesto que «la iglesia latinoamericana ha sido una vez más testigo fiel de su irrenunciable misión profética, iluminando desde la perspectiva evangélica, materias referidas al orden político, evaluando la moralidad de los hechos individuales y sociales» ${ }^{23}$. Desde la revista democristiana se respaldó la tesis de los obispos que consideraba que el gobierno militar no controlaba determinados focos represivos que serían los responsables de las violaciones a los DDHH. Incluso Augusto Conte, cuyo hijo había desaparecido unos meses antes de la publicación de "Reflexión cristiana...», envió una nota a la CEA para expresar que comprometía sus esfuerzos "para no dejar sola a nuestra Iglesia en la asunción de posiciones, bajo el pretexto de interpretar que goza de una cobertura que numerosos casos han desmentido" (VERBITSKY, 2006: I66). Esta carta previene contra explicaciones teleológicas o lineales y señala la importancia de analizar la reconfiguración de sentidos, prácticas y trayectorias en un contexto histórico extremadamente cambiante.

Un dirigente como Néstor Vicente, que en el futuro sería promotor de la candidatura de Conte y representante de la línea interna Humanismo y Liberación que disputó la conducción del partido desde posiciones de izquierda, en 1977 sostenía que el tema de la «seguridad y derechos humanos» era demasiado «ríspido» pero que había que dialogar para «restañar heridas y refundar una sociedad doblemente atacada ${ }^{24}$. La prioridad era la «unidad nacional» y ello implicaba el rechazo de las «minorías iluminadas o proféticas de izquierdas y derechas que pretenden para el país proyectos antihistóricos y disfrazados de la raíz y esencia de nuestros valores más genuinos ${ }^{25}$. Carlos Eroles, por su parte, además de avalar la idea expresada por los obispos de que el gobierno carecía de capacidad para «monopolizar el ejercicio de la fuerza», sostuvo que "las bandas subversivas de ultraizquierda y los grupos que responden a móviles de ultraderecha, continúan manejando la dialéctica del atentado personal, que han sembrado tanto desconcierto y miedo en la comunidad de los argentinos» ${ }^{26}$.

\footnotetext{
${ }^{23}$ "La Iglesia latinoamericana y los modelos sociopolíticos», Síntesis Socialcristiana, Nㅜ 1, 07/1977, p. 9. ${ }^{24}$ VICENTE, NÉSTOR, «Dialogo político (o como congeniar la realidad y la fantasía)», Síntesis Socialcristiana, No 1, 07/1977, p. 3.

${ }^{25}$ VICENTE, NÉSTOR, «Pluralismo y participación para disentir en unidad», Síntesis Socialcristiana, $N^{\circ} 2,08 / 1977$, p. 2.

${ }^{26}$ EROLES, CARLOS, «Un nuevo atentado contra la paz», Síntesis Socialcristiana, №2, 08/1977, p. 9.
} 
El distanciamiento frente a los "grupos de derecha y de izquierda» se manifestó con claridad en el citado documento «No a la violencia, sí a la paz». Allí los dirigentes democristianos apuntaron contra los «sectarismos de uno y otro signo» que habían destruido "las bases de nuestra comunidad" y caracterizaron a un pueblo que «harto ya de la inseguridad, el miedo y la frustración, anhela reencontrar el camino $»^{27}$. Finalmente, luego de aseverar que «todos tenemos nuestra cuota de responsabilidad, civiles y militares", llamaron a un dialogo que incluya a las «Fuerzas Armadas, Partidos Políticos, Iglesia, el movimiento obrero organizado, el empresariado nacional, los intelectuales, los técnicos, los profesionales, los jóvenes ${ }^{28}$.

De este recorrido es posible observar entonces que los discursos y propuestas provenientes de la autoridad eclesiástica tuvieron una amplia repercusión al interior del PDC. En momentos de indefinición sobre lo que deparaba el horizonte político, la voz de los obispos se volvió una referencia y un lugar seguro desde donde era posible realizar algunos reclamos.

\section{LOS DEMOCRISTIANOS, LA IGLESIA Y LA POLÍTICA EN LOS ALBORES DE LA DÉCADA DE 1980}

En 1980 apareció la revista Proyecto, editada por la Fundación José Manuel Estrada. La nueva publicación optó por los «valores humanistas y cristianos que singularizan a nuestro pueblo» y definió como objetivo prioritario realizar un aporte «en la búsqueda de renovados caminos de democratización, liberación integral y promoción humana ${ }^{29}$. Fue, en buena medida, una herramienta pensada para influir en el proceso de reunificación del partido y, a la vez, para reclamar la apertura democrática. En sus páginas se fue delineando una propuesta política ante el deterioro de la dictadura militar que se nutrió de los documentos $L a$ evangelización en el presente y en el futuro de América Latina del CELAM (conocido como «Documento de Puebla») e Iglesia y Comunidad Nacional de la CEA, de los mensajes del Papa y de los obispos argentinos y de otras referencias religiosas.

\footnotetext{
27 "No a la violencia, si a la Paz», Síntesis Socialcristiana, № 5, 12/1977, p. 12.

28 "No a la violencia, si a la Paz», Síntesis Socialcristiana, №5, 12/1977, p. 12.

29 Proyecto Socialcristiano, № 1, 07/1980, p. 2.
} 


\section{La Iglesia como respaldo en la lucha por la recuperación de la democracia}

$\mathrm{Al}$ iniciarse la década de 1980 el gobierno militar no mostraba una dirección clara y los proyectos políticos que se discutían puertas adentro de los cuarteles no generaban consenso en las FFAA ${ }^{30}$. A finales de I98I, las incongruencias y contradicciones quedaron plasmadas en el desplazamiento del general Roberto Viola, segundo presidente del Proceso. Los partidos políticos, por su parte, comenzaron a salir del letargo y formaron la Multipartidaria, que incluía al Partido Justicialista, la Unión Cívica Radical, el PDC, el Movimiento de Integración y Desarrollo y el Partido Intransigente. Su principal objetivo fue acelerar el retorno de la democracia, aunque, en esta primera etapa y hasta el final de la Guerra de Malvinas, que las FFAA consideraran a la Multipartidaria un interlocutor válido y establecieran algún dialogo, ya era un logro destacado. En este contexto los obispos jugaron un rol cada vez más importante y lograron -sin comprometerse explícitamente- que sus discursos constituyeran una pátina de legitimación extra política disponible para actores tan necesitados de un punto de apoyo. Los posicionamientos del grupo de dirigentes que estamos analizando iban más allá de los aportes de la Doctrina Social de la Iglesia -en torno a la cual competía con el peronismo- y, en algunos aspectos, tendían a introducir una impronta religiosa en la actividad política. En este punto se daba una coincidencia con la convocatoria de la Iglesia a los católicos para evangelizar la cultura.

$\mathrm{El}$ «Documento de Puebla» e Iglesia y Comunidad Nacional se convirtieron en una matriz para pensar la cultura, la política y el lugar de los católicos en ella. Fueron documentos que, a tono con la dirección que se venía estableciendo desde el Concilio Vaticano II, alentaron a los laicos a insertarse en los diferentes ambientes. En el primero de estos documentos, los obispos latinoamericanos caracterizaron a una sociedad en crisis, sujeta a profundas transformaciones, frente a la cual la Iglesia debía asumir un rol activo y orientar los cambios a través de la evangelización de la cultura ${ }^{31}$. A pesar de que se reconoció que la nueva evangelización debería tener en cuenta los cambios introducidos por la "civilización urbano industrial” y ofrecer una síntesis que la incluyera y la superara conjugando tradición y progreso, se reafirmó la existencia de una cultura determinada por los valores que desde la

${ }^{30}$ Sobre los proyectos políticos del Proceso ver: NOVARO y PALERMO, 2003; QUIROGA, 2004; CANELO, 2008.

31 III Conferencia General del Episcopado Latinoamericano, La evangelización en el presente y en el futuro de América Latina. Documento de Puebla. Buenos Aires, Ediciones CEA, 1979 («Documento de Puebla»). 
colonización se asociaban al cristianismo y que definía una identidad de los países de la región por sobre sus particularidades ${ }^{32}$.

Dos años después de la reunión de los obispos latinoamericanos, la CEA difundió el documento Iglesia y Comunidad Nacional. Este fue, visto en perspectiva, el documento episcopal más importante de la década y se convirtió en referencia ineludible para los documentos que le siguieron. Los partidos que integraban la Multipartidaria se apropiaron de las afirmaciones de fe democrática y de la insistencia en la reconciliación que poblaban el documento episcopal. Como sostiene Bonnin «fueron numerosos quienes, desde el sindicalismo, los partidos políticos o las organizaciones de derechos humanos, encontraron aquí una legitimidad que los acompañaba en sus reclamos» (BONNIN, 20I2: 18). Ello, para este autor, no dejó de ser paradójico en la medida en que se trataba de un texto ambiguo que reflejaba la diversidad existente dentro de la CEA. Como hemos sostenido (FABRIs, 2OII) esa ambigüedad fue un elemento fundamental en la constitución de consensos hacia el interior del cuerpo episcopal y favoreció, además, aquella utilización de las propuestas episcopales por una gama amplia de actores.

El documento rescató el progreso material, los valores democráticos y los ideales de libertad asociados a la modernidad. Sin embargo, no pasó por alto que esa misma modernidad y el liberalismo, predominante entre las elites argentinas, había desconocido los valores religiosos. Si desde «los orígenes de la América española, la Iglesia [...] contribuyó a comunicar un espíritu cristiano y evangélico que penetró la raíz misma de la cultura en gestación», 33 lo que se evidenciaba desde la segunda mitad del siglo XIX era que esos valores aportados por la Iglesia no se expresaban en "las estructuras políticas, económicas, sociales, educativas» ${ }^{34}$. A partir de esta evaluación, consideraron que la meta de la institución católica no era «sólo ofrecer a los hombres el mensaje y la gracia de Cristo, sino también impregnar y perfeccionar todo el orden temporal con el espíritu del evangelio» ${ }^{35}$. Se expresaban en estas líneas «las tensiones de la teología del Pueblo: una voluntad de pluralismo sesgada por el mito de la catolicidad del pueblo» (BONNIN, 20I2: 65).

\footnotetext{
32 «Documento de Puebla», p. 60 y pp. 67 - 68.

33 «Documento de Puebla», p. 7.

34 «Documento de Puebla», p. 14.

35 «Documento de Puebla», p. 160.
} 
Los dirigentes democristianos se hicieron eco de las propuestas contenidas en estos documentos y se comprometieron a llevar el mensaje a todos los sectores que conformaban la comunidad nacional ${ }^{36}$. El logro de la unidad y la reconciliación se podría concretar a partir del reconocimiento de los valores cristianos como matriz de la cultura popular. Carlos Eroles, uno de los más activos colaboradores de Proyecto, abogó por la evangelización de la política en consonancia con la propuesta de Puebla. ${ }^{37}$ Desde las páginas de Proyecto, Eroles convocó a los dirigentes cristianos a hacer presente «el rostro de una Iglesia comprometida en la promoción de la justicia en nuestro pueblo». ${ }^{38}$ Citando a Juan Pablo II, sostuvo que ser «laico, es asumir una praxis concreta, tendiente a evangelizar los ambientes, la cultura, las instituciones y las relaciones de convivencia de los hombres concretos ${ }^{39}$. La Iglesia no era solamente la "fuerza espiritual que reúne el mayor poder de convocatoria» sino que era «la respuesta» a los problemas cada vez más acuciantes de los pueblos latinoamericanos y para que la «respuesta» llegue a todos los rincones, los dirigentes y laicos cristianos debían ser el «eco de la palabra de la Iglesia» ${ }^{40}$.

Entre las iniciativas concretas a través de las cuales se impulsó ese compromiso, Eroles destacó al seminario «Iglesia y Comunidad Argentina en la perspectiva de Puebla» que brindó el Instituto de Cultura Religiosa Superior, del que él mismo era docente. En este seminario coordinado por Jorge Novak, obispo de Quilmes, Gerardo Farrell y Lucio Gera, ambos referentes de la Teología de la Cultura, participaron dirigentes políticos, sindicalistas, docentes y periodistas. Dado que el «Documento de Puebla» fue entendido como un «espíritu que llama al compromiso y a la acción» el seminario se propuso nuclear a los que quieren ser «los laicos de Puebla». Además, el compromiso se reforzó con la participación de los dirigentes democristianos en espacios institucionales. Carlos Eroles, por ejemplo, fue nombrado por el Episcopado como secretario de la Comisión Justicia y Paz que integraban, además, Ignacio Palacios Videla, colaborador de habitual de

\footnotetext{
${ }^{36}$ Proyecto Socialcristiano, № 1, 07/1980, p. 2.

37 «Reportaje a Osvaldo Musto: La Iglesia comprometida con la liberación el hombre concreto», Proyecto Socialcristiano, $N^{\circ} 1,07 / 1980$, pp. 8 y 9.

38 «Documento de Puebla», p. 241.

39 EROLES, CARLOS, "Los laicos de Puebla», Proyecto Socialcristiano, № 4, 10/1980, p. 2.

40 RAMOS, JUAN MANUEL, «Reportaje a Carlos Eroles: La reconciliación es, en la Argentina, el nombre de la paz», Proyecto Socialcristiano, № 11/12, 07-08/1981, pp. 8 y 9.
} 
Proyecto, y Roberto Caldo, presidente de la Junta Provincial del PDC en Buenos Aires. El caso de Palacios Videla resulta particularmente relevante ya que, si bien había abandonado el partido a principios de la década de 1970, participaba en los círculos de debate y las redes que vinculaban a los militantes democristianos y fue el único laico que tomó parte en la redacción de Iglesia y Comunidad Nacional (BONNIN, 20I2: 85-86).

La tensión señalada en el discurso de los obispos entre la aceptación del pluralismo cultural y la atribución a los valores cristianos un carácter determinante, se reprodujo en las intervenciones de los dirigentes democristianos. Así, por ejemplo, si bien Enrique De Vedia sostuvo que «La Argentina es plural y compleja [y] se expresa en una riquísima diversidad de corrientes de pensamiento», la adopción de la interpretación de Puebla y de Iglesia y Comunidad Nacional implicaba establecer un orden entre esas corrientes que las hacía dependientes del núcleo de la cultura conformado por el vínculo del hombre con la trascendencia ${ }^{41}$.

\section{La cuestión de los derechos humanos en un nuevo contexto}

Aquella lectura de la violencia política y la represión que implicaba un distanciamiento frente a dos extremos adquirió contornos más nítidos en esta etapa cuando la cuestión comenzó a emerger junto al reclamo por el retorno de la democracia. Se consideró que el pueblo, violentado por los «extremos de derecha e izquierda», estaba llamado a protagonizar un nuevo tiempo político que la debacle del gobierno militar reclamaba a gritos. Desde Proyecto el dirigente justicialista Julio Bárbaro sostuvo que «en el enfrentamiento entre izquierdas y derechas, existe un gran ausente: nuestro Pueblo, relegado a la espera de que la minoría triunfante le proponga un tiempo de nuevo sacrificio». ${ }^{42}$

Ahora bien, lo que todavía no estaba muy claro a principios de 1980 era la responsabilidad que le cabía al gobierno. La teoría de los «excesos» que diferenciaba entre una represión legítima y ciertos desbordes resultantes del accionar de grupos específicos era sostenida por algunos sectores del gobierno, la prensa, la mayoría de los dirigentes políticos y los obispos. Sólo considerando el peso de este marco

${ }^{41}$ EROLES, CARLOS, «Reportaje a Enrique De Vedia: No hay nación sin pueblo», Proyecto Socialcristiano, No 10, 06/1981, p. 9.

42 BÁRBARO, JULIO, «El espacio del centro», Proyecto Socialcristiano, № 1, 07/1980, p. 5. 
interpretativo es posible entender que los democristianos promovieran debates sobre el proyecto nacional incluyendo también a figuras del Proceso que, en el futuro cercano, se transformarían en representantes paradigmáticos del Terrorismo de Estado. Fue el caso de la Cátedra de Estudios Argentinos que funcionaba en el marco del Club Nacional, del que Néstor Vicente era secretario general. La revista definió esta iniciativa como el esfuerzo «de encontrar los valores síntesis, que permitan gestar el espacio amplio de la coincidencia argentina para afrontar la concreción del Proyecto Nacional Pendiente». En la cátedra se anunciaba la participación de los ex presidentes Arturo Frondizi y Juan Carlos Onganía, de un variado arco de dirigentes políticos, empresariales y eclesiásticos y del almirante Eduardo Massera ${ }^{43}$. En el mismo número de la revista en el que se informaba de esta participación, Carlos Auyero denunció que la sociedad argentina estaba bloqueada por la agresión que se ejercía «desde la cúpula del poder» ${ }^{44}$.

El número de septiembre de 1980 de Proyecto incluyó una declaración firmada por referentes socialcristianos pertenecientes al PPC como De Vedia, Conte, Auyero, Eroles, Di Liscia, Frugoni Rey y Bruno, entre otros, en la que se sostenía que no era

«hora de jactancias, ni de tutorías indebidas, ni de falsas antinomias. No es cuestión de enfrentamientos entre civiles y militares. Para nosotros las Fuerzas Armadas son instituciones históricas destinadas a ser custodia de la integridad territorial, brazo armado de la voluntad popular y partícipes en el desarrollo integral de la Nación y como tales no pueden ser identificadas con el pensamiento político que expresan sus conductores circunstanciales» ${ }^{45}$.

El motivo principal de esta declaración fue reclamar por el retorno de la democracia y, si bien incluyó una crítica a la política económica del gobierno militar, no hubo menciones explícitas a la cuestión de los desaparecidos. No era un tema ausente, pero, en general, aparecía asociado a una preocupación más acuciante por la unidad nacional y, en este marco, se volvían centrales los discursos de la jerarquía católica, en particular sus referencias a la reconciliación. Adolfo Pérez Esquivel, Premio Nobel de la Paz en 1980, sostuvo en las páginas de la publicación

\footnotetext{
43 Proyecto Socialcristiano, №2, 08/1980, p. 5.

44 AUYERO, CARLOS, «Soberanía popular o decadencia», Proyecto Socialcristiano, N2, 08/1980, p. 16.

45 Proyecto Socialcristiano, N³, 09/1980 p. 13.
} 
democristiana que los argentinos «tenemos que convencernos que no debemos guardar odios ni rencores, a pesar de todos los sufrimientos. Pero únicamente podremos llegar a la paz y a la Reconciliación a través de la JUSTICA EN VERDAD» ${ }^{46}$.

En esta línea, Carlos Auyero tituló su habitual columna «La reconciliación nacional en un orden justo», y propuso los medios para lograr esa reconciliación. Era necesario que el gobierno reconociera la soberanía popular, que se encontraran «los andariveles racionales» para la superación de los conflictos y que se alcanzara una paz que, según el Concilio Vaticano II, era «fruto del orden impreso a la sociedad humana por Dios, que deben realizar los hombres sedientos de una justicia cada vez más perfecta» ${ }^{47}$. En este camino, superar la violencia era una condición ineludible, «desde la artera acción del terrorismo hasta la cruel soberbia del despotismo del poder [que] son contrasignos de una sociedad que terminará por aislarlos definitivamente haciendo prevalecer los valores perdurables del mensaje evangélico que galvaniza la voluntad de la inmensa mayoría de nuestro pueblo» ${ }^{48}$.

Poco después, la revista publicó una nota basada en el «Documento de Puebla» donde reprodujo el distanciamiento frente a los extremos y además especificó, como no había ocurrido antes, las características de la represión estatal y de las violaciones a los $\mathrm{DDHH}^{49}$. Se rechazó «la tortura física y sicológica, los secuestros, la persecución de disidentes políticos o de sospechosos y la exclusión de la vida pública por causas de las ideas» ${ }^{50}$ y se consideró a la Doctrina de la Seguridad Nacional una «ideología absoluta» que no se «armonizaría con una visión cristiana del hombre en cuanto responsable de la realización de un proyecto temporal ni del Estado, en cuanto administrador del bien común ${ }^{51}$. En el mismo número, la revista incluyó un informe de Augusto Conte sobre un coloquio realizado en Francia en enero de 198I en el que se abordó «La política de las desapariciones forzadas de personas». Conte-que presentó una ponencia denunciando el carácter sistemático de la represión-destacó que el coloquio había contado con el respal-

\footnotetext{
${ }^{46}$ «Reportaje a Pérez Esquivel: El Evangelio, única respuesta», Proyecto Socialcristiano, № 5, 11/ 1980, p. 9.

47 Proyecto Socialcristiano, № 6, 12/1980, p. 16.

48 Proyecto Socialcristiano, № 6, 12/1980, p. 16.

49 SONEGO, VÍCTOR, «Terrorismo vs Derechos Humanos», Proyecto Socialcristiano, № 7, 03/1981, p. 4,

50 «Documento de Puebla», p. 184.

51 «Documento de Puebla», pp. 189-190.
} 
do del Movimiento Internacional de Juristas Católicos, de numerosos obispos latinoamericanos y del padre Pedro Arrupe, Superior de la Compañía de Jesús. La nota resaltó como una de las conclusiones más relevante del coloquio que la desaparición de personas se había producido en forma sistemática y masiva «como resultado de cursos de acción que revelan las características de una verdadera opción política». Para enfrentar la desconfianza de quienes aceptaban como válido el discurso del gobierno sobre la campaña contra el país que se orquestaba en el exterior, Conte destacó la objetividad de las presentaciones en las que no hubo «ninguna interferencia ni gravitación que obedezca a otro criterio que el de las instituciones y personalidades presentes». Finalmente, en su informe Conte lanzó un desafío al preguntarse si caeremos

«una vez más en la superficialidad y el escapismo de eludir las circunstancias que estamos obligados a afrontar...? ¿¿Simularemos aceptar la propuesta simplista y ahistórica de que el ocultamiento y el escamoteo constituyen condición para una así supuesta recomposición institucional?... ¿¿Haremos esto, o por el contrario, enfrentaremos los hechos con coraje, hombría y patriotismo, buscando respuestas sin desmayo para este inédito e insoslayable problema nacional?» ${ }^{52}$.

Es posible argumentar que el hecho de que el informe de Conte estuviera precedido por una nota sobre el tema apoyada en los documentos eclesiales -y que el mismo Conte destacara los apoyos provenientes del mundo católico- respondió a la necesidad de establecer, tal como señalamos arriba, un marco de legitimidad que evite su asociación con la «campańa Anti Argentina» que denunciaba el régimen militar. De todas maneras, si esa fue la meta perseguida, el resultado no fue el esperado. El 27 de febrero de 198I Conte fue detenido por la policía junto a Emilio Mignone y a otros miembros de los organismos defensores de derechos humanos. Según señala Catoggio, la detención de Conte estuvo directamente relacionada con su participación en el Coloquio en Paris y con las posiciones expuestas sobre la represión en Argentina (2017: 197). Proyecto informó de la detención, resaltó la participación de Conte en el PDC y destacó «su entereza y coraje civil para afrontar,

52 CONTE MAC DONELL, AUGUSTO, «Coloquio en Francia: La política de las desapariciones forzadas de personas», Proyecto Socialcristiano, № 7, 03/1981, p. 11. 
con energía y serenidad, la defensa de los derechos humanos y los valores de justicia, libertad y reconciliación $»^{53}$. La referencia a la «reconciliación» no ocupaba un lugar central en los discursos de Conte sobre los DDHH aunque sí se trataba de un valor que reconocía desde sus propias creencias religiosas. Pero aún en este caso, el significado que Conte le podía atribuir a la reconciliación, probablemente, no fuera el mismo que predominaba en la mayoría del Episcopado y que era reproducido por la dirigencia política. Lo que parecía querer significar la revista en el informe sobre su detención es que se trataba de dirigente democristiano que luchaba por la reconciliación de los argentinos y que estos atributos lo deberían haber excluido del campo de lo «reprimible». Lo cierto es que a Conte no se lo detuvo ni por su militancia democristiana ni por su labor en busca de la reconciliación, sino porque era un referente del movimiento de los DDHH. En definitiva, este hecho expresaba que «la represión a la política trasnacional (humanitaria) practicada por Conte desde el cels contrastaba con la tolerancia del régimen hacia su política partidaria en la DC» (CATOGGIO, 20I7: 197).

Cuando los obispos dieron a conocer Iglesia y Comunidad Nacional, los parámetros sostenidos en el documento sobre la violencia política, la represión y la propuesta reconciliadora pasaron a formar parte de los discursos habituales de Proyecto. En este sentido, Eroles habló de la reconciliación como «la valoración de todo sufrimiento por igual» que supone, «voluntad cierta de justicia, solidaridad y amor». Para el dirigente democristiano había que superar «odios, enfrentamientos y rencores» ${ }^{54}$ y en ese camino, la idea del «amor» era la clave. A través de este tipo de definiciones, el concepto de reconciliación adquiría un sentido un poco más nítido. Si era el amor el que la haría posible, la cuestión era cómo cultivar ese amor. En un tramo de Iglesia y Comunidad Nacional los obispos acotaron los sentidos de la reconciliación, definieron las formas del amor y establecieron una relación concreta con la justicia:

«[...] la experiencia demuestra que otras fuerzas negativas, como el rencor, el odio, la revancha e incluso la crueldad, han tomado la delantera a la justicia. Más aún, que, en nombre de la misma justicia, se ha pecado contra ella. La experiencia del

\footnotetext{
53 «Augusto Conte y Emilio Mignone: defensores del estado de derecho y la dignidad nacional», Proyecto Socialcristiano, № 8, 04/1981, pp. 8 y 9.

${ }^{54}$ RAMOS, JUAN MANUEL, «Reportaje a Carlos Eroles: La reconciliación es, en la Argentina, el nombre de la paz», Proyecto Socialcristiano, №11/12, 07-08/1981, pp. 8 y 9.
} 
pasado y de nuestros tiempos demuestra que la justicia por sí sola no es suficiente y que, más aún, puede conducir a la negación y al aniquilamiento de sí misma, si no se le permite a esa forma más profunda, que es el amor, plasmar la vida humana en sus diversas dimensiones. Necesitamos los argentinos superar aun la misma justicia mediante la solidaridad y el amor. Necesitamos, urgentemente, alcanzar esa forma superior del amor que es el perdón» ${ }^{5}$.

Estos posicionamientos fueron replicados también por Néstor Vicente a la hora de criticar al gobierno. El dirigente democristiano reclamó la movilización «de todos los sectores sociales, económicos, culturales y religiosos» $\mathrm{y}$ «aparición con vida" y propuso poner la búsqueda de acuerdos en función de la democratización «bajo el espíritu pastoral del documento del Episcopado Argentino sobre la reconciliación nacional $\aleph^{56}$.

Poco después, el propio Vicente concluyó que para gestar la salida de los militares era «indispensable asumir en su trascendente dimensión el tema de los derechos humanos». Frente a este tema y apoyado en Iglesia y Comunidad Nacional criticó el «desborde represivo con el que fue tratado el fenómeno subversivo en la Argentina» y a la "violencia guerrillera» y sostuvo que "porque se hace urgente la reconciliación argentina, queremos afirmar que ella se edifica sólo sobre la verdad, la justicia y la libertad, impregnadas en la misericordia y en el amor [...] Ni un olvido imposible ni una venganza infecunda ${ }^{57}$.

Como ya ha sido señalado (FABRIS, 20I3; BONNIN, 2OI5), la centralidad del discurso sobre la reconciliación durante la transición a la democracia se debió, en buena medida, al despliegue de una multiplicidad de sentidos que lo convirtió en un recurso al que podían apelar los actores políticos. En la etapa analizada, el sentido predominante al que acudieron los dirigentes democristianos parece haber sido aquel que se desplegaba, entre ambigüedades, en los documentos episcopales y que establecía al perdón como alternativa a la justicia.

${ }^{55}$ CEA, Iglesia y comunidad nacional, Buenos Aires, Claretiana, 1981. p. 72.

${ }^{56}$ VICENTE, NÉSTOR «Intransigencia o acuerdismo», Proyecto Socialcristiano, № 11-12, 07-08/1981, p. 10.

57 VICENTE, NÉSTOR, «Ni un olvido imposible ni una venganza infecunda», Proyecto Socialcristiano. $N^{\circ} 13-14,09-10 / 1981$, p. 5. 


\section{A MODO DE CIERRE}

Durante la dictadura militar y en las condiciones de restricción de la actividad política impuesta por las FFAA, la Iglesia acrecentó el protagonismo político que había disfrutado durante el siglo xx. El gobierno, los dirigentes políticos y la prensa se mostraban atentos a sus pronunciamientos e incluso entre los grupos defensores de los DDHH no faltó quien evaluara que un eventual respaldo eclesiástico era fundamental para la causa.

Parece bastante claro que, para dirigencias políticas debilitadas, respaldarse en la Iglesia católica, remitir a los documentos de la jerarquía o citar a un obispo era un recurso de legitimación que no se debía soslayar. A través de la invocación de fines trascendentes y superiores provenientes del ámbito extra político -que, además, eran difíciles de cuestionar cuando el interlocutor, por caso el gobierno militar, también recurría a ellos para presentarse como defensor de la «civilización occidental y cristiana»- las dirigencias políticas participaban en las luchas de poder con gobierno y, pronto, entre ellas. El discurso religioso no es ajeno a intereses políticos concretos, pero, en general, estos permanecen implícitos detrás de eufemismos que le otorgan a ese discurso toda su eficacia (BOURDieu y de SAINT MARTín, 2009). En los discursos políticos en la Argentina de principios de la década de 1980 es posible reconocer los aportes de los obispos. Puede parecer paradójico que la democracia recuperada en 1983 , que buceaba en la tradición liberal-republicana en busca de valores en los que fundarse, sea fruto de un devenir político que mucho debía al protagonismo de la Iglesia. Como se ha demostrado, esa democracia no implicó una cesura absoluta con el pasado sino más bien un reacomodamiento donde convivieron rupturas y continuidades (FABRIS, 20II).

Las posiciones de los dirigentes democristianos que reconocimos en el análisis de sus publicaciones evidencian esta tendencia a respaldarse en los discursos elaborados por la Iglesia. A su vez, la incorporación de los documentos episcopales implicó la reproducción de las tensiones propias de escritos que, en definitiva, trataban de expresar consensos entre las tendencias teológicas y políticas que convivían en la CEA. La tensión más importante, porque remite a la presencia del catolicismo en la sociedad, era aquella que se expresaba entre la aceptación del pluralismo, por un lado, y la insistencia en un núcleo de valores esenciales heredados de la colonización, por el otro. La existencia misma de un partido que reivindica la representación de quienes se identifican con el ideario cristiano implica la aceptación de una sociedad más diversa y plural y no termina de encajar con la tendencia 
a identificar un ser nacional forjado bajo el influjo del cristianismo que, de una forma u otra, implicaría concebir a la sociedad como un todo.

$\mathrm{Al}$ observar la incorporación de los discursos de la Iglesia por parte de este sector de la democracia cristiana nos enfocamos en la cuestión de los DDHH. Esta cuestión nos pareció fundamental porque fue frente a ella que la iglesia puso mayor empeño en ofrecer sus propuestas. De más está decir que las mismas no tuvieron un sentido univoco y que en ese espacio de indefinición radicó la clave de su éxito. En esta dirección, la idea de reconciliación, del perdón expresado como el «amor» necesario para cicatrizar las heridas de la sociedad, era el camino para la restitución de la unidad nacional. Es importante señalar que al abordar esta cuestión también buscamos rastrear las posiciones de un sector de la PDC que poco después promovería la candidatura de Augusto Conte bajo el lema de «el candidato de los DDHH». La proliferación, en las coyunturas consideradas, de discursos que centrados en las propuestas reconciliadoras de la Iglesia poco tenían que ver con la imagen asociada a Conte y su militancia en el movimiento de DDHH nos indica que resulta fundamental analizar estos problemas con detenimiento en un contexto de cambios políticos y de una enorme inestabilidad en las posiciones de los actores.

\section{Bibliografía}

BIANCHI, SUSANA (2001): Catolicismo y peronismo. y debates en los inicios de la posdictadura, Fondo Religión y política en la Argentina, 1943-1955, de Cultura Económica, Buenos Aires.

IEHS, Tandil.

BONNIN, JUAN (2012): Genesis política del discurso religioso, Eudeba, Buenos Aires.

BONNIN, JUAN (2015): «Los discursos sobre la reconciliación: variaciones en torno al perdón, la verdad y la justicia», en: C. Feld y M. Franco

(Dirs.), Democracia, hora cero. Actores, políticas BOURDIEU, PIERRE Y DE SAINT-MARTIN, MONIQUE (2009): «La Sagrada Familia. El episcopado francés en el campo de poder», en: P. Bourdieu, La eficacia simbólica. Religión y política, Biblos, Buenos Aires. CAIMARI, LILA (1995): Perón y la Ig/esia católica. Religión, Estado y sociedad en la Argentina (1943-1955), Ariel, Buenos Aires. 
CANELO, PAULA (2008): El proceso en su laberinto. La interna militar de Videla a Bignone, Prometeo, Buenos Aires.

CATOGGI0, MARÍA SOLEDAD (2016): Los desaparecidos de la Iglesia. El clero contestatario frente a la dictadura, Siglo XXI, Buenos Aires.

CATOGGI0, SOLEDAD (2017): «Derechos humanos, politización y partidización: del activismo trasnacional al frente democrático» en L. Donatello, F. Mallimacci y J. Pinto, Julio (Coords.), Naciones, Religiones y Globalización, Biblos, Buenos Aires. CERRO, FRANCISCO (1983): Qué es el Partido Demócrata Cristiano, Sudamericana, Buenos Aires. ESQUIVEL, JUAN CRUZ (2004): Detrás de los muros. La Iglesia católica en tiempos de Alfonsín y Menem (1983-1999), UNQUI, Buenos Aires.

EZCURRA, ANA MARÍA (1988): Ig/esia y transición democrática. Ofensiva del neoconservadurismo católico en América Latina, Puntosur, Buenos Aires. FABRIS, MARIANO (2011): Iglesia y democracia. Avatares de la jerarquía católica en la Argentina post autoritaria (1983-1989), Prohistoria, Rosario. FABRIS, MARIANO (2013): «Perdonar y reconciliarse. La Iglesia católica argentina, el retorno de la democracia y la revisión de las violaciones a los derechos humanos», en: Secuencia, México, N 85. FABRIS, MARIANO (2018 -en prensa-): «El Partido Demócrata Cristiano y la cuestión de los derechos humanos en los años finales de la última dictadura militar. El influjo de la Iglesia y la candidatura de Augusto Conte», en: Revista Latino-Americana de Historia, UNISINOS, Rio Grande do Sul. FERRARI, MARCELA (2017): «La Democracia Cristiana argentina durante la dictadura cívico-militar y la transición temprana (1976-1985)», en Revista Historia, Santiago de Chile, vol. 50, № 1.

FERRARI, MARCELA (2018): «Democracia Cristiana, Partido Justicialista y política de frentes. El FRE-
JUDEPA en perspectiva histórica», en: Boletín del Instituto de Historia Argentina y Americana Dr. Emilio Ravignani, $\mathrm{n}^{\circ} 48$.

GHIRARDI, ENRIQUE (1983): La Democracia Cristiana, CEAL, Buenos Aires.

MAINWARING, SCOTT Y SCULLY, TIMOTHY (2010): «La diversidad de la democracia cristiana en Latinoamérica», en: S. MAINWARING y T. SCULLY (Eds.), La democracia Cristiana en América Latina, Fondo de Cultura Económica, México.

NOVARO, MARCOS Y PALERMO, VICENTE (2003): La dictadura militar, 1976-1983, Paidos, Buenos Aires. PARERA, RICARDO (1986): Los democratacristianos argentinos. Testimonios de una experiencia política. Tomo I, Ed. Leonardo Buschi, Buenos Aires. QUIROGA, HUGO (2004): El tiempo del Proceso. Conflictos y coincidencias entre políticos y militares 1976-1983, Homo Sapiens, Rosario.

SCANNONE, JUAN (1997): «Perspectivas eclesiológicas de la teología del pueblo en la Argentina», en: F. CHICA, S. PANIZZOLO y H. WAGNER (Eds.), Ecclesia Tertii Millennii Advenientis. Omaggio al P. Angel Antón, Piemme, Casale Monferrato. SPINELLI, MARÍA ESTELA (2005): Los vencedores vencidos: el antiperonismo y la revolución libertadora, Biblos, Buenos Aires.

TOURIS, CLAUDIA (2007): «Tensiones en el campo católico. La cuestión del peronismo después de 1955», en: Anuario IEHS, Tandil, № 22.

VERBITSKY, HORACIO (2006): Doble juego. La Argentina católica y militar. Buenos Aires, Sudamericana. VEZZETTI, HUGO (2002): Pasado y Presente. Guerra, Dictadura y Sociedad en la Argentina, Buenos Aires, Ed. Siglo XXI.

ZANCA, JOSÉ (2013): Cristianos antifascistas, Siglo $X X I$, Buenos Aires.

ZAZPE, VICENTE (1977): La Patria busca su futuro, Bonum, Buenos Aires. 